\title{
A Rede de Serviços de Saúde como Estratégia de Humanização no Atendimento às Mulheres Vítimas de Violência
}

\author{
Conti, Elaine Teixeira da Costa; Machado, Dinair Ferreira; Pierini, Andrea Silveira \\ Machado; Almeida, Margareth Ap Santini de; Castanheira, Elen Rose Lodeiro \\ Prefeitura Municipal de Botucatu Secretaria de Assistência Social Central de Cadastro Único - \\ elaine-conti@hotmail.com
}

Introdução: a violência contra a mulher tornou-se nas últimas décadas uma preocupação para a Saúde Pública, uma vez que envolve não somente o cuidado médico, mas um olhar multiprofissional sobre os fatores sociofamiliares e culturais que interferem diretamente na condição saúde-doença da população, neste caso, da mulher vítima de violência. Além de ações para identificar e prevenir destaca-se a importância da rede de serviços para a identificação, notificação e intervenção em casos de violência, pois a falta do trabalho em rede e a desarticulação impedem que casos de violência contra a mulher sejam identificados e que se proceda à intervenção técnica profissional adequada. a humanização no atendimento é um fator que contribui para o olhar ampliado dos profissionais e garante um atendimento integral, possibilitando assim novas articulações da rede para o caso, cujas necessidades não se esgotam apenas em um serviço. Objetivos: Identificar e mapear as abordagens realizadas pelos profissionais dos serviços de saúde de um município do interior paulista no atendimento às mulheres vítimas de violência e os procedimentos adotados para intervenção multiprofissional. Métodos: a presente pesquisa é um recorte de um projeto de pósdoutorado. Inicialmente, será identificado o tipo de violência cometida contra a mulher e o perfil socioeconômico, familiar e cultural das vítimas e agressores, através da análise de informações dispostas nos boletins de ocorrências elaborados na Delegacia de Defesa da Mulher. Posteriormente, com as mulheres que relataram terem sofrido violência há mais de cinco anos, será realizada análise das trajetórias destas na rede de serviços de saúde do município, e por fim será realizada entrevista individual e gravada para identificar os determinantes socioculturais e familiares que as levaram a conviver por tanto tempo com o parceiro. Resultado: Acredita-se que os serviços de saúde não conseguiram detectar a violência sofrida por meio dos atendimentos, tendo em vista que todas as mulheres recorreram à medida extrema de denúncia e realização de Boletins de ocorrência. Os serviços disponibilizados para atenção às mulheres vítimas de violência não estavam preparados para atendê-las integralmente, o que as levaram, a uma verdadeira peregrinação, devido à desarticulação da rede. da mesma forma, acredita-se que a abordagem profissional é fragmentada, o que se supõe que a visão ainda continue sobre o fator biomédico e não sobre os biopsicossociais, havendo a necessidade de um olhar ampliado para a oferta de política pública de qualidade e de humanização no atendimento. Conclusão: o atendimento humanizado às mulheres vítimas de violência é de extrema importância, tendo em vista que por meio deste, haverá não somente a detecção dos casos, mas também a articulação da rede de serviços.

Conti, Elaine Teixeira da Costa; Machado, Dinair Ferreira; Pierini, Andrea Silveira Machado; Almeida, Margareth Ap Santini de; Castanheira, Elen Rose Lodeiro. A Rede de Serviços de Saúde como Estratégia de Humanização no Atendimento Às Mulheres Vítimas de Violência.. In: Anais do Congresso Internacional de Humanidades \& Humanização em Saúde [= Blucher Medical Proceedings, num.2, vol.1]. São Paulo: Editora Blucher, 2014. ISSN 2357-7282

DOI 10.5151/medpro-cihhs-10378 